Revista de Derecho núm. 56 (2021): 35-5I

Pontificia Universidad Católica de Valparaíso

DOI I0.4I5I/So718-685120210056-1332

RECIBIDO 24 de abril de 202I - ACEPTADO 9 de agosto de 202I

ARTíCULOS DE INVESTIGACIÓN

\title{
Producciones de agentes artificiales
}

Creations of artificial agents

\author{
Carlos Amunátegui Perelló \\ Pontificia Universidad Católica de Chile
}

\section{RES UMEN}

El presente artículo trata acerca del estatuto de los agentes artificiales y de las producciones que realizan. En este sentido, se pregunta sobre sus creaciones y debate la posibilidad de protegerlas a través de nuestro sistema de propiedad intelectual. La metodología será histórica y comparativa. Los resultados consisten en establecer el estatuto de las creaciones realizadas por dichos agentes.

\section{PALABRAS CLAVE}

Inteligencia artificial $\cdot$ derechos de autor $\cdot$ cosas corporales $\cdot$ cosas ideales frutos · productos.

\section{ABSTRACT}

This article aims to research the legal status of artificial agents $y$ and their creations. It asks about its creations and debates the possibility of giving copyright protecton to them. The methodology is historical and comparative. As a result we present a legal framework for the creations of artificial agents.

\section{KEY WORDS}

Artificial intelligence $\cdot$ copyright $\cdot$ incorporal things $\cdot$ ideal things $\cdot$ fruits . products. 


\section{INTRODUCCIÓN}

Ya hace años que los agentes artificiales realizan producciones que, si fuesen hechas por humanos, no dudaríamos en darles la protección que el derecho de autor otorga. Composiciones musicales, cuadros, ${ }^{1}$ fotografías, artículos de prensa ${ }^{2}$ y hasta algún guion cinematográfico ${ }^{3}$ han aparecido íntegramente compuestos por modelos de inteligencia artificial. Las preguntas que emergen de estos hechos son: cuál es el estatuto jurídico vigente para tales obras, quién es su titular y si es que pueden ser protegidas con derechos de autor.

El objetivo de este artículo es responder a estas tres simples preguntas teniendo como marco el derecho actualmente vigente. Para ello, primeramente analizaremos el estatuto jurídico de los agentes artificiales en nuestro sistema civil. Seguidamente, trataremos las producciones que realizan y su apropiación para dedicar un acápite aparte al caso de que tales productos fuesen obras que, de ser creadas por seres humanos, estarían bajo derechos de autor. Finalmente, resumiremos nuestras conclusiones.

\section{ESTATUTO DE LOS AGENTES ARTIFICIALES}

En primer término, debemos explorar el problema del estatuto de los agentes artificiales. En principio, el esquema jurídico heredado del siglo XIX propone una división entre cosas y personas: todas las entidades que existan deben adscribirse a uno de estos dos polos jurídicos. Por una parte, están los sujetos de derechos, las personas, titulares de derechos y, por otra, los objetos de tales derechos, las cosas. Esta concepción hunde sus raíces en las disquisiciones de Savigny sobre la materia, quien estableció esta distinción en el vértice sobre el cual dibujará su sistema de derecho. En este sentido, según el autor, las personas establecerían relaciones jurídicas

${ }^{1}$ De hecho, un cuadro compuesto en 2018 por redes adversariales fue rematado en Christie’s por más de cuatrocientos mil dólares. Un comentario de la casa de remates está disponible en https://bit.ly/3jDW 7 AU. Consultado el I3 de noviembre de 2020.

${ }^{2}$ El más famoso es aquel aparecido el 8 de septiembre de 2020 en The Guardian, donde el modelo de lenguaje $\mathrm{GTP}_{3}$ defiende la idea de que los agentes artificiales no son peligrosos para la humanidad. Para más información, véase https://bit.ly/3kQeVwg. Consultado el I3 de noviembre de 2020.

3 Nos referimos a Sunspring, el extraño corto de ciencia ficción construido sobre el guion elaborado en base a alimentar una red neuronal con guiones de películas de terror. Para más información, véase https://bit.ly/2WOlpni. Consultado el I3 de noviembre de 2020. 
mediante el uso de su voluntad, ${ }^{4}$ mientras que, en la medida que ejerzan estas relaciones sobre partes de la naturaleza, estas serían cosas. ${ }^{5}$

En este sentido, los agentes artificiales, al menos hasta el momento en que se escriben estas líneas, son universalmente considerados cosas, objetos de derechos, y no cuentan con ningún tipo de atributo de la personalidad. Si bien hay bastantes argumentos para construir un estatuto propio para los agentes artificiales, ${ }^{6}$ incluyendo una declaración del Parlamento Europeo $^{7}$ que recomienda su otorgamiento como un método para fijar su responsabilidad, e incluso, en algunos foros académicos, acusaciones de especismo para quienes no estén dispuestos a admitir un estatuto similar, ${ }^{8}$ la verdad es que actualmente no cabe duda de su adscripción al mundo de las cosas. Dentro de este, nuestra investigación debe iniciarse en lo relativo al tipo de cosas a que corresponden, toda vez que nuestro Código Civil adoptó la distinción entre cosas corporales e incorporales en la materia.9

Nuestro Código, en su artículo 565, distingue entre cosas corporales e incorporales. Las primeras son las que tienen un ser real y pueden dis-

${ }_{4}$ "Puede definirse la relación de derecho diciendo que es el dominio de la voluntad libre». SAvigny, Karl Frederich, Sistema del derecho romano actual (traducción de Jacinto Mesía y Manuel Poley, Madrid, Góngora, I878), p. 224.

5 "No podemos dominar la naturaleza no libre en su totalidad, sino únicamente en una porción determinada, separada de su conjunto; esta parte, asi eliminada, se llama cosa, y aqui comienza la primera clase de derechos, el derecho a una cosa que, bajo su forma más pura y más completa, se llama propiedad». SAvignY, Karl Frederich, cit. (n. 4), p. 226. Por otra parte, no obstante, en el derecho antecedente precodificado, tal diferencia no era del todo prístina, como se menciona en Guzmán BRITo, Alejandro, Los orígenes de la noción de sujeto de derecho, en Revista de Estudios Histórico-Jurídicos 24 (2002), pp. 15I-250. En derecho romano persona no significaba sujeto de derecho, ni todos los seres humanos tenían la categoría de sujetos, como se menciona en STAGL, Jakob F., De cómo el hombre llegó a ser persona: Los origenes de un concepto jurídico-filosófico en el derecho romano, en Revista de Derecho (Pontificia Universidad Católica de Derecho), 45 (2015) 2, pp. 373-40I.

${ }^{6}$ En nuestro medio, véase Chávez Valdivia, Ana Karin, No es solo un robot: Consideraciones en torno a una nueva personalidad jurídica y el redimensionamiento de las relaciones interpersonales, en Ius et Praxis 26 (2020) 2, pp. 55-77.

7 European Parliament Resolution with recommendations to the Commission on Civil Law Rules on Robotics (2015/2103 (INL)).

${ }^{8}$ Ryder, Richard, Speciesim Again: The Original Leaflet, Critical Society 2 (2010), pp. I-2.

9 Es menester mencionar que, mientras el Código francés - y con él la mayor parte de las codificaciones decimonónicas - desechó tal distinción, con la salvedad del Código holandés de 1829 (véase GuZMán Brito, Alejandro, Las cosas incorporales en la doctrina y en el derecho positivo (Santiago, Editorial Jurídica de Chile, 2006), p. 40), Andrés Bello sí la incluyó en su codificación y desde ahí irradió en la tradición codificadora latinoamericana. 
tinguirse por los sentidos, mientras que las segundas consisten en meros derechos, lo cual envuelve una cierta incoherencia, toda vez que existen cosas imperceptibles por los sentidos, pero que, no obstante, no tienen una consistencia jurídica. Tal clasificación hunde sus raíces en aquella realizada por el jurista romano Gayo en sus Institutas, ${ }^{10}$ donde adapta la distinción entre corpora (bienes) y iura (derechos) que venían haciendo juristas anteriores, ${ }^{\text {II }}$ con la particularidad de modificarla para sus propios fines pedagógicos. Los bienes corporales, en Gayo, serán aquellos objetos de dominio, mientras que los incorporales serán todos los demás derechos diversos del dominio, que podrán ser derechos en cosas ajenas (servidumbres personales y reales), derechos sobre universalidades (como las herencias) u obligaciones, lo cual le permitirá al jurista desarrollar su texto para cubrir todas las particularidades relativas a los objetos de derecho en los libros segundo y tercero de su obra. Así, y a pesar de la incoherencia inmanente en la contraposición entre cosas perceptibles y derechos, la ventaja sistemática que implicaba terminó por popularizarla y fue recogida por las Instituciones de Justiniano, ${ }^{\mathrm{I} 2}$ de donde pasó a la tradición jurídica occiden-

10 Gai 2.I2. Quaedam praeterea res corporales sunt, quaedam incorporales. I3. Corporales hae sunt, quae tangi possunt, uelut fundus, homo, uestis, aurum, argentum et denique aliae res innumerabiles. I4. Incorporales sunt, quae tangi non possunt, qualia sunt ea, quae in iure consistunt, sicut hereditas, ususfructus, obligationes quoquo modo contractae. nec ad rem pertinet, quod in hereditate res corporales continentur, et fructus, qui ex fundo percipiuntur, corporales sunt, et id, quod ex aliqua obligatione nobis debetur, plerumque corporale est, ueluti fundus, homo, pecunia: nam ipsum ius successionis et ipsum ius utendi fruendi et ipsum ius obligationis incorporale est. eodem numero sunt iura praediorum urbanorum et rusticorum. $[\ldots \ldots v .2 \mathrm{I} / 4 \ldots \ldots$.$] non extollendi, ne luminibus uicini officiatur: item fluminum et$ stillicidiorum idem ius ut [ . . . vv. 5. . . . . ].

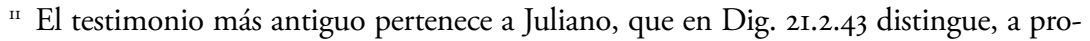
pósito del parto de la vaca, entre cosas corporales y derechos: Dig. 2I.2.43 Iulianus libro 58 digestorum. Vaccae emptor, si vitulus qui post emptionem natus est evincatur, agere ex duplae stipulatione non potest, quia nec ipsa nec usus fructus evincitur. Nam quod dicimus vitulum fructum esse vaccae, non ius, sed corpus demonstramus, sicuti praediorum frumenta et vinum fructum recte dicimus, cum constet eadem haec non recte usum fructum appellari. Desde Juliano, la distinción entre corpora y iura fue utilizada repetidamente por diversos juristas tardo-clásicos. Para una historia detallada, véase: GuzMán BRito, Alejandro, cit. (n. 9), p. 26.

${ }^{12}$ Inst. Just. 2.2 Quaedam praeterea res corporales sunt, quaedam incorporales. I. Corporales eae sunt quae sui natura tangi possunt: veluti fundus, homo, vestis, aurum, argentum et denique aliae res innumerabiles. 2. Incorporales autem sunt quae tangi non possunt. qualia sunt ea quae in iure consistunt: sicut hereditas, usus fructus, obligationes quoquo modo contractae. nec ad rem pertinet quod in hereditate res corporales continentur: nam et fructus qui ex fundo percipiuntur corporales sunt, et id quod ex aliqua obligatione nobis debetur plerumque corporale est, veluti fundus, homo, pecunia: nam ipsum ius hereditatis et ipsum ius utendifruendi et ipsum ius obligationis incorporale est. 
tal. ${ }^{13}$ En este contexto es que debe analizarse si es que los agentes artificiales son consistentes con las cosas corporales o incorporales, toda vez que su estatuto jurídico se distingue en diversos aspectos, como su circulación y prescripción adquisitiva.

En principio, los agentes artificiales son métodos de manipulación simbólica o algoritmos, ejecutables por ordenadores que realizan funciones que en los humanos requerirían de actos cognitivos. ${ }^{14}$ Estos pueden revestir dos formas, ya que unos tienen mecanismos para interactuar con el mundo físico, en cuyo caso se denominan robots, ${ }^{15} \mathrm{y}$ otros carecen de métodos de intervención directa en el mundo real, con la salvedad de unidades de salida —output — que expresan los resultados de sus procesos. En este sentido, un agente artificial es una entidad compuesta por partes de diversa naturaleza que adquiere unidad en su función. Así, aplicarles la categoría romana de cosas compuestas tiene sentido, pues los agentes artificiales son una síntesis de elementos (hoc est pluribus inter se cohaerentibus constat, quod sunymmenon vocatur ${ }^{16}$ que adquieren unidad por estar unidos entre sí ejecutando una función.

Ahora bien, con respecto a su corporalidad o incorporalidad, claramente los agentes artificiales no son derechos, en el sentido de que no tienen una consistencia jurídica. La categoría de cosas incorporales no pa-

${ }^{13}$ A pesar de que el Code Napoléon no recogió dicha tradición, esta sí fue recibida por los primeros comentaristas del mismo, particularmente en la obra de DELVINCOURT, Claude Etienne, Cours de Code Civil (Dijon, Videcoq, I834), I, pp.I39-I43, que es la fuente próxima de donde la recogerá Bello para su propia codificación.

${ }^{14}$ Una buena definición de trabajo es aquella que entregan Russell y Norvig: «The field of artificial intelligence, or AI, is concerned with not just understanding but also building intelligent entities -machines that can compute how to act effectively and safely in a wide variety of novel situations». Russell, Stuart y Norvig, Peter, Artificial intelligence. A modern approach (Hoboken, Pearson, 2020), p.I.

is Tomamos como definición de trabajo aquella ofrecida por Russell y Norvig en su clásico libro de texto sobre la materia: «Robots are physical agents that perform tasks by manipulating the physical world». Russell, Stuart y Norvig, Peter, cit. (n. I4), p. 924. La palabra robot proviene de la obra teatral de Karel Čapek, Robots Universales Rossum, en la que el autor describe una sociedad en que la firma Rossum fabrica esclavos (robota en checo) artificiales que terminan por rebelarse en contra de sus amos.

${ }^{16}$ Dig. 4I.3.30 Pomponius libro 30 ad Sabinum. pr. Rerum mixtura facta an usucapionem cuiusque praecedentem interrumpit, quaeritur. Tria autem genera sunt corporum, unum, quod continetur uno spiritu et Graece hynwmenon [continuum] vocatur, ut homo tignum lapis et similia: alterum, quod ex contingentibus, hoc est pluribus inter se cohaerentibus constat, quod sunymmenon vocatur, ut aedificium navis armarium: tertium, quod ex distantibus constat, ut corpora plura non soluta, sed uni nomini subiecta, veluti populus legio grex. Primum genus usucapione quaestionem non habet, secundum et tertium habet. 
rece aplicable a ellos y, por defecto, caerían dentro de las cosas corporales. Ahora bien, puede alegarse que su consistencia es inmaterial toda vez que son procedimientos o algoritmos. Esto es cierto, a lo menos con respecto a una parte de ellos, si olvidamos que muchos cuentan con elementos para ser percibidos en el mundo y no nos referimos solo a los robots, como un automóvil autoconducido, sino también a cualquier programa que requiere de unidades de entrada para captar datos, procesamiento, para realizar manipulación simbólica, y salida, para expresar sus resultados (input, output y processing unit, en nomenclatura de Turing). ${ }^{17}$ Los agentes artificiales son unidades concebidas como la unión de elementos materiales e inmateriales por una función determinada. La parte inmaterial o algoritmo se expresa en el mundo material cuando actúa y, en este sentido, es perceptible por los sentidos, sea en la forma de imágenes, sonido o como quiera que sea que se conciba su unidad de salida. En definitiva, los agentes artificiales son cosas corporales, toda vez que no son derechos y pueden hacerse perceptibles por los sentidos cuando actúan a través de sus unidades de salida.

Ahora bien, sobre los agentes artificiales también pueden recaer derechos de autor. En efecto, la parte más importante de cualquier agente artificial es el programa computacional que le sirve de base. Dichos programas o modelos son creaciones intelectuales y, como tales, se encuentran protegidos, tanto desde el punto de vista moral como desde los derechos patrimoniales que generan. En este sentido, tanto la Declaración Universal de Derechos Humanos de $1948,{ }^{18}$ como nuestra Constitución Política, ${ }^{19}$

${ }_{17}$ Este es el modelo básico de todo ordenador, que se encuentra inmanente en el diseño de la máquina de Turing, Alan, On computable numbers, with an application to the Entscheidungsprobleme, Proceedings of the London Mathematical Society 2 (1937) 42, pp. 230-265.

${ }_{18}$ Artículo 27, número I: "Toda persona tiene derecho a tomar parte libremente en la vida cultural de la comunidad, a gozar de las artes y a participar en el progreso cientifico y en los beneficios que de él resulten. 2. Toda persona tiene derecho a la protección de los intereses morales y materiales que le correspondan por razón de las producciones cientificas, literarias o artisticas de que sea autora».

19 Constitución Política de la República, artículo 19, número 25: «La libertad de crear y difundir las artes, asi como el derecho del autor sobre sus creaciones intelectuales y artísticas de cualquier especie, por el tiempo que señale la ley y que no será inferior al de la vida del titular. El derecho de autor comprende la propiedad de las obras y otros derechos, como la paternidad, la edición y la integridad de la obra, todo ello en conformidad a la ley. Se garantiza, también, la propiedad industrial sobre las patentes de invención, marcas comerciales, modelos, procesos tecnológicos u otras creaciones análogas, por el tiempo que establezca la ley. Será aplicable a la propiedad de las creaciones intelectuales y artísticas y a la propiedad industrial lo prescrito en los incisos segundo, tercero, cuarto y quinto del número anterion. 
contemplan la protección de tales aspectos, en nuestro caso, como una forma de propiedad.

Ya desde el Código Civil, los derechos de autor son concebidos como una forma de propiedad, de conformidad a su artículo 584. Dicho texto, tomado del Proyecto de García Goyena (artículo 393) y, más remotamente, del Código Sardo (artículo 440), ${ }^{20}$ consagra la adhesión de nuestro sistema jurídico al modelo francés de Droit d'Auteur, frente al copyright, propio del common law. ${ }^{2 \mathrm{I}}$

Ahora bien, la Ley I7.336 o Ley de Propiedad Intelectual protege los programas computacionales mediante el sistema de derechos de autor. Esta es una forma discutible de llevar la protección intelectual de ellos, pero fue aquella internacionalmente elegida en razón de las modificaciones de la Convención de Berna. ${ }^{22}$ Al respecto, el artículo 3, número i6, de la referida ley declara objeto de protección de propiedad intelectual a los programas computacionales en los siguientes términos: "Los programas computacionales, cualquiera sea el modo o forma de expresión, como programa fuente o programa objeto, e incluso la documentación preparatoria, su descripción técnica y manuales de uso».

La norma está inspirada en el artículo 96-I de la Ley I/I996 de Propiedad Intelectual española ${ }^{23}$ y, al respecto, comenta Walker Echeñique: «Los

${ }^{20}$ Para la historia de la propiedad intelectual en Chile durante el siglo XIX, véase el estupendo estudio de InFAnTe MarTín, Javier, Proteger lo original: consideraciones en torno a la protección de la propiedad intelectual e industrial durante la primera etapa de la legislación patria, RChD: Creación y Pensamiento, 46 (2019) I, pp. 253-278. De conformidad al mismo, la protección de los derechos de autor en Chile comienza con una real orden de Carlos III de 1778, incluida en la Novísima Recopilación de Leyes de España (Nov. Rec. L.8, T.I6, L.23). No obstante, hay labor legislativa al respecto en I8I3, y un reconocimiento constitucional de ella en 1833 . Finalmente, la primera Ley de Propiedad Literaria y Artística en Chile, que data de I834. El Código Civil, en este sentido, se suma a dicha tradición emergente en el primer derecho patrio.

${ }^{21}$ En verdad, la inmersión de Chile en el modelo francés de Droit d'Auteur se remonta a la consagración constitucional de la propiedad intelectual en la Constitución de I833. Al respecto, véase: Cerda Silva, Alberto, Evolución histórica del derecho de autor en América Latina, en Ius et Praxis 22 (2016) I, p. 24.

${ }_{22}$ Berkemeyer, Hugo, Desafíos de la propiedad intelectual, en Velasco Santelices, Rodrigo - Morales Andrade, Marcos (coordinadores), Homenaje a Arturo Alessandri Besa. Estudios de derecho y propiedad intelectual (Santiago, Editorial Jurídica de Chile, 2010), p. 127.

${ }^{23}$ L.I/1996, artículo 96.I: "A los efectos de la presente Ley se entenderá por programa de ordenador toda secuencia de instrucciones o indicaciones destinadas a ser utilizadas, directa o indirectamente, en un sistema informático para realizar una función o una tarea o para obtener un resultado determinado, cualquiera que fuere su forma de expresión y fijación. A los 
programas computacionales originalmente podian ser protegidos extendiendo la noción de obras literarias, considerando que dichos trabajos están compuestos por un lenguaje de programación, conocido como "programa fuente" o "código fuente". Dicha relación entre programa computacional y obras literarias sigue vigente en algunos paises, tales como el Reino Unido. El "programa fuente" contrasta con el "programa objeto", consistente en la "traducción" que se realiza del lenguaje de programación con la finalidad de que el computador pueda procesar las instrucciones $y$, de tal forma, el programa computacional pueda funcionar de forma adecuada. A diferencia del "programa fuente" que se estructura por un lenguaje que utiliza palabras reconocibles por los seres humanos, el "programa objeto" se compone de diversas combinaciones de los números I y 0.24 ".

Un punto importante es que un programa computacional es meramente un medio de expresión a través del cual se puede manifestar, en un ordenador, un conjunto de instrucciones para que represente diversas realidades. Así, una imagen computacional es un programa de ordenador, lo mismo que un video, un artículo periodístico, una novela o estas mismas páginas, que son escritas mediante tal dispositivo. Así, el bien protegido a través de propiedad intelectual no es meramente el conjunto de instrucciones, sino también el resultado de su ejecución, esto es, el objeto creado, de conformidad al ya transcrito artículo 3, número 16, de la Ley 17.336. De esta manera, cualquier creación, en la medida que sea expresable en código fuente, puede ser objeto de protección de derechos de autor mediante su consideración como programa computacional. En este sentido, tales programas pueden ser objeto de derechos de autor y, por tanto, quedarán bajo el ámbito de protección de la Ley 17.336.

Ahora bien, sobre los agentes artificiales pueden establecerse derechos, que serían cosas de carácter incorporal, como los de autor. No obstante, y dependiendo de la técnica utilizada para su configuración, la protección otorgada puede resultar incompleta, toda vez que, en los modelos formados por redes neuronales, el programador solo diseña la configuración de la red, más el aprendizaje en sí del modelo y, por tanto, su capacidad para actuar eficientemente es el resultado de un proceso de entrenamiento. Las redes neuronales adquieren sus funciones a través de su exposición a ejemplos, de los cuales aprenden los pesos (weights) que deben otorgar a sus

mismos efectos, la expresión programas de ordenador comprenderá también su documentación preparatoria. La documentación técnica y los manuales de uso de un programa gozarán de la misma protección que este Título dispensa a los programas de ordenadon.

24 Walker Echeñique, Elisa, Manual de propiedad intelectual (Santiago, Thomson Reuters, 20I4), p. 88. 
conexiones con otras redes para obtener resultados satisfactorios. Nada de ello es "programado", sino que se entrena en el modelo y son propiamente comportamientos aprendidos. Resulta discutible que tales características, que son las más valiosas del modelo, puedan ser objeto de derechos de autor. ${ }^{25}$ Otro punto importante es que los algoritmos, mientras se encuentren expresados de una forma puramente matemática, se encuentran fuera del ámbito de protección, y que solo adquieren el estatuto de obras protegibles cuando han sido expresados en lenguaje computacional o código fuente. ${ }^{26} \mathrm{La}$ única forma de darle protección integral a los modelos de inteligencia artificial parece ser a través de su consideración como secretos comerciales, lo cual resulta altamente problemático.

En cuanto al titular de los derechos de autor que eventualmente puedan recaer en un agente artificial, en principio, estos pueden recaer en el propio programador o en la persona natural o jurídica que lo emplee, o bajo cuyo encargo se haya producido. ${ }^{27}$ En este sentido, en muchos casos, el titular original de los mismos no será quien efectivamente los haya programado, sino, en caso de realizar tal labor por cuenta de un tercero, será este quien sea considerado como autor. Haciendo excepción a las normas generales, ese tercero puede ser una persona natural o jurídica. Ahora bien, en nuestro sistema jurídico, siguiendo la tradición continental de los Droits d'Auteur, se contemplan tanto derechos patrimoniales como morales relativos a la autoría. No cabe duda de que la ley cede los derechos patrimoniales a la persona bajo cuya dependencia o encargo se realizó la obra, pero hay buenos argumentos para dudar de que esto se extienda a los derechos morales, ${ }^{28}$ toda vez que estos corresponden a una manifestación de la personalidad y se vinculan estrictamente a los derechos humanos del programador.

${ }^{25}$ En este sentido, afirma Buyers: «It would seem evident in this context that at least the AI Model (the logical framework within which the system operates) described above will potentially be elegible for copyright protection». Buyers, John, Artificial Intelligence. The Practical Legal Issues (Somerset, Law Brief Publishing, 2018), p. 57.

${ }^{26}$ Buyers, John, cit. (n. 25) p. 59.

27 Artículo 8, Ley 17.336, incisos segundo y tercero: «Tratándose de programas computacionales, serán titulares del derecho de autor respectivo las personas naturales o jurídicas cuyos dependientes, en el desempeño de sus funciones laborales, los hubiesen producido, salvo estipulación escrita en contrario». "Respecto de los programas computacionales producidos por encargo de un tercero, se reputarán cedidos a éste los derechos de su autor, salvo estipulación escrita en contrario».

${ }^{28}$ Sierra Herrero, Alfredo y Bernet Páez, Manuel Antonio, Régimen jurídico de los programas computacionales elaborados por trabajadores en Chile, en Ius et Praxis 26 (2020) 2, p. 257. 
En definitiva, en este acápite podemos concluir que los agentes artificiales son, en principio, cosas corporales, objeto de diversos derechos que pueden constituirse sobre ellos. Por una parte, está el dominio propiamente tal, que recae sobre el bien, y adicionalmente puede ser objeto de derechos de autor. Si el programador los modela para sí, entonces tendrá todos los derechos patrimoniales y morales que la Ley 17.336 otorga a los autores, pero si los diseńa bajo dependencia o por encargo de un tercero, los derechos patrimoniales pertenecerán a este, mientras que los derechos morales debiesen mantenerse vinculados a su creador efectivo. Una vez establecido el estatuto de ellos, podemos pasar a tratar el problema relativo a las producciones que son resultado del actuar de tales agentes.

\section{BIENES PRODUCIDOS POR AGENTES ARTIFICIALES}

Los agentes artificiales son capaces de producir diversos bienes de alto valor, especialmente porque, en caso de ser realizados por seres humanos, requerirían el uso del intelecto.

Los bienes producidos pueden ser cosas corporales -especialmente en el caso de los robots-, servicios, predicciones e incluso bienes que, de ser realizados por seres humanos, serían protegibles por derechos de propiedad intelectual, como piezas de música, artículos periodísticos u otros bienes. La propiedad de tales bienes pertenece, en principio, a quien sea dueño del agente, mediante la accesión de frutos. En este sentido, el artículo 643 del Código Civil señala: "La accesión es un modo de adquirir por el cual el dueño de una cosa pasa a serlo de lo que ella produce, o de lo que se junta a ella. Los productos de las cosas son frutos naturales o civiles."

Así, las producciones que realiza un agente artificial son sus frutos $y$, por tanto, son de titularidad de su dueño. Ulpiano ${ }^{29}$ señala que fruto es lo que nace de un bien o lo que se puede percibir de él, de donde proviene nuestra definición de fruto del artículo 644 del Código. En este sentido, un agente artificial produce diversos tipos de frutos, los cuales pueden ser cedidos a terceros, transformando las ganancias económicas que provienen de dichos actos en sus frutos civiles. Mientras una predicción financiera que realice un agente artificial será su fruto natural, el precio de la cesión de tales predicciones será su fruto civil..$^{\circ}$

29 Dig.7.I.9.pr. Ulpianus libro I7 ad Sabinum. Item si fundi usus fructus sit legatus, quidquid in fundo nascitur, quidquid inde percipi potest, ipsius fructus est, sic tamen ut boni viri arbitratu fruatur. Nam et Celsus libro octavo decimo digestorum scribit cogi eum posse recte colere.

30 Si bien GuZmán Brito señala que las cosas ideales no producen frutos naturales 
Ahora bien, no solo el dueño de un agente artificial puede apropiarse de los frutos emanados de su actividad. También, quien sea su usufructuario o arrendatario se hace dueño de los bienes que produzca, de conformidad a los artículos 78I, 790 y I9I9 del Código, por simple aplicación de las reglas generales del derecho civil.

Si el agente es objeto de derechos de autor, en este caso las producciones del agente son también de propiedad del titular de los derechos de autor. En este sentido, la propiedad intelectual se comporta como una suerte de monopolio establecido a favor del autor de una obra o del creador de una idea para que este la explote en exclusiva o designe a quienes pueden legítimamente explotarla. No obstante la especialidad de los derechos de autor, es ella una especie de propiedad (artículo 584 del Código Civil), por lo que se le aplican las normas generales relativas a la propiedad común en la medida en que su naturaleza lo permita, por lo que, aunque usualmente los bienes objeto de derecho de autor no generen frutos, en el caso de los agentes artificiales, cuyo estatuto se asemeja al de los esclavos, sí existe tal virtualidad.

En general, los derechos de autor son «derechos que, por el solo hecho de la creación de la obra, adquieren los autores de obras de la inteligencia en los dominios literarios, artísticos y cientificos, cualquiera que sea su forma de expresión» (artículo I, Ley 17.336). Así, el autor o titular original puede ceder sus derechos patrimoniales a un titular secundario que podrá apropiarse de los bienes..$^{3 \mathrm{I}}$ En este sentido, el adquirente ocupará la posición de un titular secundario y se hará con sus frutos..$^{32} \mathrm{La}$ forma contractual que se utilice puede ser muy variada, pero, en principio, será el arrendamiento la predominante, donde el titular original otorga el «goce o aprovechamiento temporal de una obra protegida por el derecho de autor a cambio de un beneficio económico o comercial». ${ }^{33}$ En este sentido, el arrendatario adquiere, justamente, el goce de la cosa, esto es, la facultad de apropiarse de los frutos naturales o civiles que produzca.

(GuZMÁn Brito, Alejandro, cit. (n. 9), p. 55), es menester admitir que tradicionalmente este planteamiento era correcto, pero en el caso de los agentes artificiales dicha regla general no parece aplicable, toda vez que estos sí son capaces de generar bienes de diversa naturaleza a través de su actuar. Son similares a los esclavos de la época romana, en este sentido, que sí producen frutos a través de su labor.

${ }^{31}$ Ley 17.336, artículo 7: "Es titular original del derecho el autor de la obra. Es titular secundario del derecho el que la adquiera del autor a cualquier título».

${ }^{32}$ Ley 17.336, artículo 20: «Se entiende, por autorización el permiso otorgado por el titular del derecho de autor, en cualquier forma contractual, para utilizar la obra de alguno de los modos y por alguno de los medios que esta ley establece».

33 Walker Echeñique, Elisa, cit. (n. 24), p. 168. 
Ahora bien, toca preguntarse por la posibilidad de que un agente artificial produzca una obra que, en caso de ser generada por un ser humano, ameritaría el otorgamiento de la protección de los derechos de autor. ${ }^{34}$ No cabe duda de que una melodía, imagen o texto producido por un ser humano es protegible a través de este régimen. ¿Qué sucede con aquellas realizadas por un agente artificial? La respuesta no es clara, ni en nuestro derecho, ni en el derecho comparado. Este es un problema mucho menos reciente de lo que suele concebirse. En los hechos, los agentes artificiales han producido obras desde hace décadas. ${ }^{35}$ En efecto, hay patentes de invención por obras generadas por agentes artificiales que se remontan a $1998,{ }^{36} \mathrm{o}$ incluso invenciones no patentadas desde $1983 .{ }^{37}$ No obstante, es en época más reciente que las capacidades creativas de los agentes artificiales se hacen tan obvias que el problema se torna candente.

En derecho comparado, la situación no es del todo prístina. En Estados Unidos, de momento, la Copyright Office se ha pronunciado por la negativa. $\mathrm{Al}$ respecto, ha señalado, en la última edición de su Compendio de Prácticas, que solo registrará obras producidas por un ser humano. ${ }^{38}$ Esta posición fue tomada por primera vez por la Copyright Office en 1973, aunque existen intentos fallidos de registrar obras que datan desde la década de $1950^{39}$ con respecto a ciertas obras que fueron calificadas como arte abstracto.

Una posición diametralmente opuesta, en cambio, es aquella asumida por el Reino Unido. Al efecto, ya en I988, estableció la posibilidad de que las obras producidas por agentes artificiales fuesen susceptibles de protección mediante copyright. Así, en el artículo 9 de la Copyright, Designs

${ }_{34}$ Véase al respecto el excelente artículo de Azuaje Pirela, Michelle, Productos de la inteligencia artificial en el sistema de propiedad intelectual, en Revista Jurídica Austral I (2020) I, pp. 319-342.

${ }_{35}$ Аввотт, Ryan, The reasonable robot. Artificial intelligence and the law (Cambridge, Cambridge University Press, 2020), p. Io.

${ }^{36}$ Аввотт, Ryan, cit. (n. 35), p. 73.

37 Schwarz, A.F., Handbook of VLSI Chip Design and Expert Systems (London, Academic Press, 1993), p. 216.

${ }^{38}$ "The U.S. Copyright Office will register an original work of authorship, provided that the work was created by a human being». Compendium of US Copright Office Practices, del 29 de septiembre de 20I7, en particular los capítulos 306 y 313.2.

39 Abbott lo expone en los siguientes términos: «Since at least 1973, the US Copyright Office has formally conditioned copyright registration on human authorship, although applicants report that the Copyright Office has rejected submissions for AI generated works as far back as 1957". Аввотт, Ryan, cit. (n. 35), p. 79. 
and Patents $\mathrm{Act}^{40}$ estableció que, en el caso de obras artísticas generadas por medios informáticos, fuese estimada autor la persona que realizó los «necessary arrengements» para su realización. En cuanto a quien sería esa persona, el punto no ha sido completamente aclarado. En el único litigio sobre la materia que conocemos, ${ }^{4 \mathrm{I}}$ el problema no fue solucionado y se mantuvo una cierta tensión entre la protección otorgada a un diseño gráfico y el programa en que se expresa.

En cuanto a la Unión Europea, no existe normativa comunitaria que se exprese sobre el punto, y hasta donde conocemos, tampoco los Estados miembros de la Unión han tomado partido, aunque parece desprenderse de las disposiciones generales que asume que el autor es siempre un ser humano. ${ }^{42}$

Nuestro sistema jurídico parece asumir una posición similar a aquella de la Unión Europea, toda vez que, cuando define los diversos tipos de autor, siempre parece estar pensando en personas naturales, y de hecho lo expresa así en dos letras del artículo 5 de la Ley 17.336.43 Ahora bien, la redacción cambia sutilmente cuando pasa a tratar sobre los programas computacionales en el inciso segundo de su artículo 8: «Tratándose de programas computacionales, serán titulares del derecho de autor respectivo las personas naturales o jurídicas cuyos dependientes, en el desempeño de sus funciones laborales, los hubiesen producido, salvo estipulación escrita en contrario».

Este inciso fue introducido en 1990 por la Ley I8.957 y, excepcionalmente, considera autor a una persona jurídica. ${ }^{44} \mathrm{La}$ intención de la norma es que, en el caso de los programas computacionales producidos bajo relación laboral, se estime titular de los derechos de autor al empleador. Esto genera variadas dudas que no han sido resueltas como, por ejemplo, si la norma se refiere tan solo a los derechos patrimoniales o también a los morales, toda vez que estos son inalienables y pueden ser considerados como un derecho

$4^{\circ}$ "In the case of a literary, dramatic, musical or artistic work which is computer-generated, the author shall be taken to be the person by whom the arrangements necessary for the creation of the work are undertaken". Artículo 9, Copyright Designs and Patents Act de 1988.

${ }^{41}$ Nova Productions Ltd v Mazooma Games Ltd and others: CA i4 Mar 2007. [2007] EWCA Civ 219, [2007] Bus LR I032.

${ }_{42}$ Turner, Jacob, Robot rules. Regulating artificial intelligence (London, Palgrave Macmillan, 2019), 1. 3126. Véase también: Azuaje Pirela, Michelle, cit. (n. 34), p. 333.

${ }_{43}$ Artículo 5, Ley 17.336: «Para los efectos de la presente ley, se entenderá por: «a) Obra individual: la que sea producida por una sola persona natural; b) Obra en colaboración: la que sea producida, conjuntamente, por dos o más personas naturales cuyos aportes no puedan ser separados».

${ }^{44}$ Walker Echeñique, Elisa, cit. (n. 24), p. 7 y 2 I. 
propiamente humano. ${ }^{45}$ Incluso, podría sostenerse que tales obras no son objeto propiamente de derechos morales, sobre todo en el caso de que no tengan un autor identificable. Ahora bien, el inciso tercero del mismo artículo agrega una norma interesante sobre el punto: «Respecto de los programas computacionales producidos por encargo de un tercero, se reputarán cedidos a este los derechos de su autor, salvo estipulación escrita en contrario».

Esta disposición también fue introducida por la Ley I8.957 y se refiere a la creación de obras por encargo. En este sentido, si un tercero crea un programa computacional a través, por ejemplo, de un arrendamiento de obra u otra forma contractual similar, se presume que los derechos de propiedad intelectual han sido cedidos a la persona que encargó tal modelo.

Ambas disposiciones podrían ser interpretadas de manera que las obras creadas por agentes artificiales se encontrasen comprendidas en ellas. En principio, cualquier imagen, pieza de música, video o texto escrito creado por un agente artificial puede ser expresado en código fuente y usualmente lo será. ${ }^{46}$ En este sentido, la gran mayoría de las obras creadas por agentes artificiales son programas, por lo que el objeto expresado en ellos cabría dentro de la norma.

Las obras creadas por agentes artificiales pueden ser consideradas creadas por entidades bajo la dependencia o por encargo de quien se sirve de ellos. Si bien no existe la relación laboral a la que se refiere el inciso segundo, pues un modelo computacional no es un trabajador, la expresión "por encargo» de la que se sirve el inciso tercero del artículo 8 de la Ley I7.336 es suficientemente amplia como para hacer caber cualquier relación de titularidad que exista entre el agente y la persona que se sirve de él. Así, si un agente artificial crea una imagen, esta es la expresión objetiva de un programa computacional, y al haber sido creada por encargo de la persona que se sirve de él, los derechos de propiedad intelectual se radicarían en tal persona, que puede ser natural o jurídica. En este sentido, creemos, las obras creadas por agentes artificiales podrían ser objeto de protección de derechos de autor sirviéndonos de la normativa actualmente vigente, y el titular de tales derechos no sería otro que la persona que encarga la

$45 \mathrm{Al}$ respecto, véase Sierra Herrero, Alfredo y Bernet Páez, Manuel Antonio, cit. (n. 28), pp.254-273; Walker Echeñique, Elisa, cit. (n. 24), p.96; Schuster, Santiago, Derechos de autor en las relaciones laborales y su vinculo con el tratadode libre comercio entre Chile y Estados Unidos, en Velasco Santelices, Rodrigo - Morales Andrade, Marcos (coordinadores), Homenaje a Arturo Alessandri Besa. Estudios de derecho y propiedad intelectual (Santiago, Editorial Jurídica de Chile, 2010), p. 369.

${ }_{46}$ Ocasionalmente pueden encontrarse robots que pinten con pinceles o interpreten en un instrumento convencional piezas de música, pero esto no es lo más común. 
obra o dispone los medios para su ejecución, en términos similares a la ley británica.

Ahora bien, la protección, en nuestra opinión, debiese limitarse a los derechos patrimoniales emanados del derecho de autor, toda vez que aquellos denominados morales parecen proteger una condición subjetiva propia de la naturaleza humana y que en nada revisten paralelo con respecto a las creaciones realizadas por un agente artificial.

\section{Conclusiones}

Quisiéramos resumir brevemente las conclusiones parciales a las que hemos llegado en este artículo. En primer término, los agentes artificiales son cosas, toda vez que no tenemos elementos para considerarlos de ninguna otra manera. Como tales, caen en la categoría de cosas corporales y, por tanto, son objeto de derechos. Pueden incluir también cosas incorporales, como derechos de autor, aunque la protección que tal estatuto entrega a los programas computacionales es insuficiente en la medida que no incluye el entrenamiento del que pueden ser objeto para realizar sus funciones.

Las obras que producen los agentes artificiales son sus frutos y, por tanto, se hacen de su titular mediante la accesión de frutos del Código Civil, ya sea que consistan en información, en bienes físicos o en el valor obtenido por su cesión a título oneroso (frutos civiles). Estos frutos pueden ser para su propietario o para la persona a quien se haya cedido su goce, ya sea mediante un derecho real o una relación contractual, como el arrendamiento.

Si los bienes producidos por el agente son de aquellos que, en caso de ser creados por un ser humano, producirían protección en virtud de derechos de autor, es dudoso si pueden ser protegidos. En principio, en la medida que sean expresados como un programa computacional, esto es, a través de código fuente reproducible por un ordenador, sí podrían protegerse en nuestro ordenamiento por aplicación de los incisos segundo y tercero del artículo 8 de la Ley 17.336, quedando, al menos, los derechos patrimoniales bajo la titularidad de la persona que encargó su ejecución.

Quisiéramos destacar que, en caso de no otorgarse protección de derechos de autor a las creaciones de agentes artificiales, lo más probable es que tales obras sean falsamente atribuidas a seres humanos a fin de lograr este objetivo, y terminaría por desvirtuar el objetivo perseguido por los derechos de autor, introduciendo serias distorsiones en nuestro sistema jurídico y económico. De hecho, a lo menos en el área relativa a patentes de invención, esto parece ser lo que actualmente ocurre. ${ }^{47}$

\footnotetext{
47 «In 20I9, Siemens reported that it had been unable to file for protection on mul-
} 


\section{BiBLIOGRAFÍA}

Аввотт, Ryan, The reasonable robot. Artificial intelligence and the law (Cambridge, Cambridge University Press, 2020).

Azuaje Pirela, Michelle, Productos de la inteligencia artificial en el sistema de propiedad intelectual, en Revista Jurídica Austral I (2020) I.

Berkemeyer, Hugo, Desafios de la propiedad intelectual, en Velasco Santelices, Rodrigo - Morales Andrade, Marcos (coordinadores), Homenaje a Arturo Alessandri Besa. Estudios de derecho y propiedad intelectual (Santiago, Editorial Jurídica de Chile, 20ro).

Buyers, John, Artificial Intelligence. The Practical Legal Issues (Somerset, Law Brief Publishing, 2018).

Cerda Silva, Alberto, Evolución histórica del derecho de autor en América Latina, en Ius et Praxis 22 (2016) I.

Chávez Valdivia, Ana Karin, No es solo un robot: Consideraciones en torno a una nueva personalidad juridica y el redimensionamiento de las relaciones interpersonales, en Ius et Praxis 26 (2020) 2.

Delvincourt, Claude Etienne, Cours de Code Civil (Dijon, Videcoq, I834), I.

Guzmán Brito, Alejandro, Los orígenes de la noción de sujeto de derecho, en Revista de Estudios Histórico-Jurídicos 24 (2002).

GuZmán Brito, Alejandro, Las cosas incorporales en la doctrina y en el derecho positivo (Santiago, Editorial Jurídica de Chile, 2006).

Infante Martín, Javier, Proteger lo original: consideraciones en torno a la protección de la propiedad intelectual e industrial durante la primera etapa de la legislación patria, RChD: Creación y Pensamiento, 46 (2019) I.

Russell, Stuart y Norvig, Peter, Artificial intelligence. A modern approach (Hoboken, Pearson, 2020).

Ryder, Richard, Speciesim Again: The Original Leaflet, Critical Society 2 (2OIO).

SAvignY, Karl Frederich, Sistema del derecho romano actual (traducción de Jacinto Mesía y Manuel Poley, Madrid, Góngora, I878).

SCHUSTER, Santiago, Derechos de autor en las relaciones laborales y su vinculo con el tratadode libre comercio entre Chile y Estados Unidos, en VeLASCO Santelices, Rodrigo - Morales Andrade, Marcos (coordinadores), Homenaje a Arturo Alessandri Besa. Estudios de derecho y propiedad intelectual (Santiago, Editorial Jurídica de Chile, 20Io).

tiple AI-generated inventions... Meanwhile, patent offices have likely been granting patents on AI-generated inventions for decades -but only because no one's disclosing AI's involvement». Аввотт, Ryan, cit. (n. 35), p. го. 
Schwarz, A.F., Handbook of VLSI Chip Design and Expert Systems (London, Academic Press, 1993).

Sierra Herrero, Alfredo y Bernet Páez, Manuel Antonio, Régimen jurídico de los programas computacionales elaborados por trabajadores en Chile, en Ius et Praxis 26 (2020) 2.

STAGL, Jakob F., De cómo el hombre llegó a ser persona: Los orígenes de un concepto jurídico-filosófico en el derecho romano, en Revista de Derecho (Valparaiso) 45 (2015) 2.

Turing, Alan, On computable numbers, with an application to the Entscheidungsprobleme, Proceedings of the London Mathematical Society 2 (1937) 42.

Turner, Jacob, Robot rules. Regulating artificial intelligence (London, Palgrave Macmillan, 20I9).

Walker Echeñique, Elisa, Manual de Propiedad Intelectual (Santiago, Thomson Reuters, 20I4).

SOBRe El AUTOR

Carlos Amunátegui Perelló es profesor de Derecho Romano en la Facultad de Derecho de la Pontificia Universidad Católica de Chile. Su correo electrónico es camunate@uc.cl. (1) https://orcid.org/oooo-ooo27063-2770. 
